\title{
What do we currently know about nutrition and bone health in relation to United Kingdom public health policy with particular reference to calcium and vitamin $\mathbf{D}$ ?
}

\author{
R. M. Francis* \\ Musculoskeletal Unit, Freeman Hospital, University of Newcastle upon Tyne, Newcastle upon Tyne, NE7 7DN, UK \\ (Received 30 March 2007 - Revised 7 June 2007 - Accepted 11 June 2007)
}

Public health policy in the UK related to nutrition and bone health has been shaped by reports from the Department of Health (DH), Food Standards Agency and WHO. Dietary reference values (DRV) for a number of nutrients were published in 1991 by the DH Committee on Medical Aspects of Food and Nutrition Policy. The subsequent DH report on nutrition and bone health in 1998 concentrated particularly on Ca and vitamin D, but also briefly addressed the effect of body weight, alcohol and other nutrients. Although this reviewed more recent evidence relating to the effect of higher intakes of $\mathrm{Ca}$ and vitamin $\mathrm{D}$ from longitudinal and interventional studies, no changes were made to the existing DRV. The Food Standards Agency published a report from their Expert Group on Vitamins and Minerals in 2003, which recommended safe upper limits for eight vitamins and minerals, with guidance provided on a further twenty-two nutrients, where there was less information on safety. The WHO report on diet, nutrition and the prevention of chronic diseases in 2003 addressed the prevention of osteoporosis, making recommendations on $\mathrm{Ca}$, vitamin $\mathrm{D}, \mathrm{Na}$, fruit and vegetables, alcohol and body weight. The present paper examines current views on what constitutes an adequate dietary Ca intake and optimal vitamin D status, the DRV for vitamin D in subjects with little or no exposure to sunlight and the results of recent epidemiological studies on the relationship between fracture risk and body weight, alcohol intake and the consumption of other nutrients.

Bone health: Public health policy: Calcium: Vitamin D

Bone diseases such as osteoporosis and osteomalacia are a major cause of excess mortality, morbidity and health and social services expenditure in older individuals, because of their association with low trauma fractures and skeletal deformity. The importance of $\mathrm{Ca}$ and vitamin $\mathrm{D}$ in the maintenance of bone health has stimulated interest in the potential role of other nutritional factors.

A number of reports and documents have shaped and influenced public health policy on nutrition and bone health in the UK. The UK Department of Health Committee on Medical Aspects of Food and Nutrition Policy (COMA) report on dietary reference values (DRV) in 1991 included nutrients relevant to bone health ${ }^{1}$. The Department of Health Advisory Group on Osteoporosis report in 1994 suggested that DRV should be reviewed, in the light of more recent studies ${ }^{2}$. This was undertaken in the Department of Health report on nutrition and bone health in 1998, which particularly concentrated on $\mathrm{Ca}$ and vitamin $\mathrm{D}^{3}$. Other nutritional factors were addressed briefly, including body weight, protein, vitamins $\mathrm{K}$ and $\mathrm{C}, \mathrm{Mg}, \mathrm{P}, \mathrm{Na}, \mathrm{K}$, fluorine, alcohol, caffeine and phyto-oestrogens ${ }^{3}$.

The Food Standards Agency Expert Group on Vitamins and Minerals published a report on safe upper limits of nutrients in
2003, which included a detailed review of nutritional and toxicological data on thirty-four vitamins and minerals ${ }^{4}$. Safe upper limits were recommended for eight of the nutrients, whilst guidance was provided for twenty-two vitamins and minerals where the evidence was less clear, including those related to bone health. Ca supplementation up to $1500 \mathrm{mg} / \mathrm{d}$ was regarded as safe, as was vitamin $\mathrm{D}$ up to $25 \mu \mathrm{g}$ (1000 IU) daily and vitamin A up to $1500 \mu \mathrm{g}$ retinol equivalents daily ${ }^{4}$.

The WHO published a report on diet, nutrition and the prevention of chronic diseases in $2003^{5}$. The osteoporosis section suggested that in countries with a high fracture incidence, low Ca intake $(<400-500 \mathrm{mg} / \mathrm{d})$ was associated with increased risk in older individuals. It was suggested that an increase in dietary intake of vitamin $\mathrm{D}$ and $\mathrm{Ca}$ in this group could reduce fracture risk. If sunshine exposure was limited, a vitamin D intake of 5-10 $\mu \mathrm{g}(200-400 \mathrm{IU})$ daily was also recommended. This report also summarised the evidence that other nutritional factors either increased or decreased the risk of fracture ${ }^{5}$. Although many studies have examined the effect of nutrition on markers of bone health, such as biochemical markers of bone turnover and bone mineral density (BMD), fracture is the most important outcome measure. 


\section{Dietary requirements for calcium}

DRV for Ca were set by the Committee on Medical Aspects of Food and Nutrition Policy in 1991, based on factorial calculations which take into account the efficiency of $\mathrm{Ca}$ absorption, obligatory losses in the faeces, urine and sweat and the requirements for growth in childhood ${ }^{1}$. The reference nutrient intake (RNI) of $700 \mathrm{mg} / \mathrm{d}$ for adults, which should provide sufficient $\mathrm{Ca}$ for $97.5 \%$ of the adult population, is two standard deviations above the estimated average requirement of $550 \mathrm{mg} / \mathrm{d}$. The lower RNI is $400 \mathrm{mg} / \mathrm{d}$, below which dietary $\mathrm{Ca}$ is likely to be inadequate, is two standard deviations lower than the estimated average requirement. No other measure of bone health was considered in 1991, but the subsequent report in 1998 examined the effects of high $\mathrm{Ca}$ intakes on BMD and fracture incidence in longitudinal and intervention studies ${ }^{3}$. This report endorsed the earlier DRV (Table 1), but it was felt that the additional $550 \mathrm{mg} / \mathrm{d}$ in lactation was probably unnecessary.

\section{Dietary calcium intake in the United Kingdom}

The major source of $\mathrm{Ca}$ is dairy produce, but other Ca-rich foods include flour, cereals, fish such as sardines and vegetables such as spinach and broccoli. The National Diet and Nutrition Survey showed that $79 \%$ of boys and girls aged 11-14 years have a dietary $\mathrm{Ca}$ intake lower than the RNI, with $12 \%$ of boys and $24 \%$ of girls in this age group having an intake below the lower $\mathrm{RNI}^{6}$. In contrast, only $2 \%$ of men and $5 \%$ of women aged 19-64 years have a dietary intake below the lower $\mathrm{RNI}^{7}$. In older women, the proportion with a $\mathrm{Ca}$ intake below the lower $\mathrm{RNI}$ increases from $8 \%$ between the ages of 65 and 74 years to $15 \%$ at 85 years and older, whereas the corresponding figures for men are $4 \%$ and $2 \%$ respectively $^{8}$.

\section{Calcium supplementation}

In view of the potentially inadequate dietary $\mathrm{Ca}$ intake in children and older individuals, it is important to review the effects of supplementation on bone health. A recently published meta-analysis of fifteen randomised controlled trials involving 2859 children examined the effects of the addition of 300$1200 \mathrm{mg}$ elemental $\mathrm{Ca}$ in supplementation or dairy produce ${ }^{9}$.

Table 1. Dietary reference values for calcium in the $\mathrm{UK}^{1,3}$

\begin{tabular}{lcc}
\hline & RNI $(\mathrm{mg})$ & LRNI $(\mathrm{mg})$ \\
\hline Childhood & & \\
$0-12$ months & 525 & 240 \\
$1-3$ years & 350 & 200 \\
$4-6$ years & 450 & 275 \\
$7-10$ years & 550 & 325 \\
$11-18$ years (male) & 1000 & 480 \\
11-18 years (female) & 800 & 450 \\
Adulthood & & \\
19+ years & 700 & 400 \\
Lactation & $+550^{*}$ & \\
\hline
\end{tabular}

RNI, reference nutrient intake; LRNI, lower reference nutrient intake. ${ }^{\star}$ The additional requirement may not be required during lactation ${ }^{3}$.
The duration of $\mathrm{Ca}$ supplementation ranged from 8 months to 4 years and post-supplementation follow up from 8 months to 8 years. This meta-analysis concluded that there was no significant effect of $\mathrm{Ca}$ supplementation on femoral neck or lumbar spine BMD. There was a small effect on total body bone mineral content and upper-limb BMD, but it is felt that this was unlikely to influence the risk of subsequent fractures. There is some debate about the appropriateness of using BMD as a single marker of bone health in children and adolescents, where considerations about skeletal mass and size are also required ${ }^{10}$.

A meta-analysis of $\mathrm{Ca}$ supplementation examined fifteen randomised controlled trials in 1806 postmenopausal women with BMD or fractures as outcome measures ${ }^{11}$. Ca decreased bone loss by $1.66(95 \%$ CI $0.92,2.39) \%$ at the spine, $1.64(95 \%$ CI $0.70,2.57) \%$ at the hip and 2.05 (95\% CI $0.24,3.86) \%$ for total body BMD. Despite this beneficial effect on bone loss, there was no reduction in the risk of vertebral fractures (relative risk 0.77 (95\% CI $0.54,1.09$ )) or non-vertebral fractures (relative risk 0.86 (95\% CI $0.43,1.72)$ ).

The Women's Health Initiative Study of Ca and vitamin D supplementation was performed in 36282 post-menopausal women aged 50-79 years ${ }^{12}$. These were randomised to receive $\mathrm{Ca}(1000 \mathrm{mg})$ and vitamin $\mathrm{D}(10 \mu \mathrm{g} ; 400 \mathrm{IU})$ or placebo daily. Although $\mathrm{Ca}$ and vitamin $\mathrm{D}$ supplementation resulted in a small beneficial effect on bone loss, there was no overall reduction in fractures, clinical vertebral fractures or hip fractures. Post hoc analysis suggested that Ca and vitamin D supplementation decreased the risk of fractures in older individuals and in those who remained compliant with treatment. Nevertheless, any potential benefits were offset by an increased risk of renal stones (hazard ratio 1.17 (95\% CI 1.02, 1.34)). Other studies show that although $\mathrm{Ca}$ supplementation increases the risk of renal stones, a high dietary intake of $\mathrm{Ca}$ is associated with a lower risk of renal stones $^{13}$.

The results of these studies suggest that the DRV for Ca in the UK are appropriate and do not support the routine use of Ca supplementation in the general population. Nevertheless, a significant proportion of younger adolescents and older individuals have a dietary $\mathrm{Ca}$ intake lower than the DRV and may benefit from an increased $\mathrm{Ca}$ intake.

\section{Dietary requirements for vitamin D}

The major source of vitamin D is cutaneous production, following exposure to UV radiation. The diet generally provides smaller amounts of vitamin $\mathrm{D}$, but this source is essential when cutaneous production is limited, because of lack of exposure to sunlight. The major dietary sources of vitamin $\mathrm{D}$ are fortified margarine and other fat spreads, cereals, oily fish, meat eggs and dairy produce. The most important consequence of vitamin D deficiency is the development of osteomalacia, which is characterised by an impairment of bone mineralisation and accumulation of osteoid. The DRV for vitamin D set in 1991 were based on the dietary amount required to ensure that the serum 25-hydroxyvitamin D (25OHD) in winter was above $20 \mathrm{nmol} / \mathrm{l}$, as vitamin D-deficiency osteomalacia generally only occurs in individuals with lower circulating concentrations ${ }^{1}$. When the DRV for vitamin D 
were reviewed by the Department of Health Nutrition and Bone Health report in 1998, no changes to the RNI were made $^{3}$. No RNI was set for children above the age of 3 years or adults below the age of 65 years, unless they were considered at risk of vitamin D deficiency (because of strict dress code, being house-bound or having increased skin pigmentation) when an RNI of $10 \mu \mathrm{g}$ (400 IU) daily was set. It is important to consider if this RNI is adequate in individuals with no cutaneous production of vitamin $\mathrm{D}$, such as completely veiled women or submariners. In the latter group, vitamin D intakes of $15 \mu \mathrm{g}$ (600 IU) daily are required to maintain serum $25 \mathrm{OHD}$ at its previous level ${ }^{14}$. As the mean intake of vitamin $\mathrm{D}$ from food sources in adults in the UK ranges $2 \cdot 0-4 \cdot 0 \mu \mathrm{g}(80-160 \mathrm{IU})$ daily $^{7,8}$, most individuals at risk of developing vitamin $\mathrm{D}$ deficiency will require supplementation. This should probably be administered as vitamin $\mathrm{D}_{3}$ (cholecalciferol) rather than vitamin $\mathrm{D}_{2}$ (ergocalciferol), as there is evidence suggesting that the metabolism of the latter may be impaired $^{15}$. In a study of twenty normal healthy men, a single oral dose of $1.25 \mathrm{mg}$ (50000 IU) of either vitamin $\mathrm{D}_{2}$ or vitamin $\mathrm{D}_{3}$ was administered, following which the change in serum $25 \mathrm{OHD}$ was monitored over a $28 \mathrm{~d}$ period. Although there were similar increases in serum 25OHD in the first $3 \mathrm{~d}$ after the administration of vitamin $\mathrm{D}_{2}$ and vitamin $\mathrm{D}_{3}$, at the end of the study the serum $25 \mathrm{OHD}$ was $50 \mathrm{nmol} / 1$ above baseline after vitamin $\mathrm{D}_{3}$ administration, but was $5 \mathrm{nmol} / 1$ lower than the initial value in the vitamin $D_{2}$-treated group ${ }^{15}$.

\section{Vitamin D deficiency in the United Kingdom}

The prevalence of vitamin D deficiency in older individuals in the UK was examined in the National Diet and Nutrition Survey $^{8}$. Using a threshold value of serum 25OHD of $<25 \mathrm{nmol} / \mathrm{l}$, the prevalence of vitamin D deficiency increased from $5-6 \%$ between the ages of 65 and 74 years to $13-25 \%$ above the age of 85 years. The prevalence of vitamin D deficiency in care-home residents was higher than $36 \%$. Similar findings were reported in the recent Health Survey for England ${ }^{16}$.

Although classically vitamin D deficiency has been associated with osteomalacia, there has been growing interest in the role of vitamin D insufficiency and secondary hyperparathyroidism in the development of osteoporosis and low trauma fractures ${ }^{17}$. There is an inverse relationship between serum 25OHD and parathyroid hormone, but no clear evidence of a threshold value of $25 \mathrm{OHD}$ above which parathyroid hormone reaches a plateau ${ }^{18}$. The relationship between $250 H D$ and parathyroid hormone may be used to establish a threshold value for vitamin D insufficiency, but there is no clear agreement on the appropriate level to select ${ }^{19}$. This may have been aggravated by the use of different assays for serum $25 \mathrm{OHD}^{20}$.

Lips has classified vitamin D insufficiency as mild (serum 25OHD 25-50 nmol/l), moderate (serum 25OHD $12.5-$ $25 \mathrm{nmol} / \mathrm{l}$ ) and severe (serum 25OHD $<12.5 \mathrm{nmol} / \mathrm{l})^{17}$. North American experts have suggested that higher levels of $25 \mathrm{OHD}$ are essential not only to maintain bone health ${ }^{19}$, but also for mental health, prevention of cancers, cardiovascular health, and for the prevention of skin and autoimmune disorders ${ }^{21}$. Holick \& Jenkins suggest that a healthy $25 \mathrm{OHD}$ is between $75-150 \mathrm{nmol} / 1$, whilst the minimum for cell health is $75 \mathrm{nmol} / 1$ and the minimum for bone health is
$50 \mathrm{nmol} / \mathrm{l}^{21}$. Relatively few individuals in the UK achieve these levels of $25 \mathrm{OHD}$ in winter and spring, when over $80 \%$ of 45 -year-old men and women have a serum concentration $<75 \mathrm{nmol} / \mathrm{l}^{22}$.

Heaney et al. examined the effects of different doses of vitamin $\mathrm{D}$ supplementation in sixty-seven men living in Omaha (NE, USA $)^{23}$. These men were treated with oral vita$\min \mathrm{D}_{3}$ at $0,25,125$ or $250 \mu \mathrm{g}$ daily for 20 weeks during the winter. Serum $25 \mathrm{OHD}$ measurements were performed regularly during this time. The maximum serum 25OHD achieved with $25 \mu \mathrm{g}$ daily was approximately $75 \mathrm{nmol} / \mathrm{l}$, whilst the values for $125 \mu \mathrm{g}$ daily were $140 \mathrm{nmol} / 1$ and that for $250 \mu \mathrm{g}$ was $200 \mathrm{nmol} / \mathrm{l}$. A recent paper reviewed the optimal serum 25OHD concentration suggested by experts and the doses of oral vitamin $D_{3}$ required to achieve these levels ${ }^{19}$. Heaney et al. suggested that a $25 \mathrm{OHD}$ of $80 \mathrm{nmol} / 1$ was appropriate, which required an oral vitamin D intake of $40 \mu \mathrm{g}$ (1600 IU) daily ${ }^{19}$. Although this is higher than the daily upper intake of $25 \mu \mathrm{g}$ (1000 IU) vitamin D recommended by the Food Standards Agency Expert Group on Vitamins and Minerals ${ }^{4}$, a recent review suggests that intakes as high as $250 \mu \mathrm{g}$ $(10000 \mathrm{IU})$ daily are $\mathrm{safe}^{24}$, at least in the short term.

\section{Vitamin D supplementation}

A meta-analysis of vitamin D supplementation published in 2005 indicated that doses of $17 \cdot 5 \cdot 20 \mu \mathrm{g}$ (700-800 IU) daily decreased the risk of hip and other non-vertebral fractures, whereas lower doses $\left(10 \mu \mathrm{g} ; 400 \mathrm{IU}\right.$ daily) were ineffective ${ }^{25}$. A number of recent studies cast doubt on the role of vitamin D supplementation, with or without $\mathrm{Ca}$, in the prevention of fractures in older individuals ${ }^{12,26-30}$. A recent Cochrane review ${ }^{31}$, which includes some of these recent studies ${ }^{26-28}$, suggests that vitamin D used alone has no significant effect on hip fracture (seven trials; 18668 participants; relative risk 1.17 (95\% CI $0.98,1.41)$ ). In contrast, combined supplementation with vitamin D and Ca marginally reduced the risk of hip fractures (seven trials; 10376 participants; relative risk 0.81 (95\% CI $0.68,0.96)$ ), but the effect appeared to be restricted to those living in institutional care ${ }^{31}$. Another recent meta-analysis also shows a similar reduction in hip fractures with $\mathrm{Ca}$ and vitamin D (relative risk 0.82 (95\% CI $0.71,0.94)$ ), with no beneficial effect of vitamin $\mathrm{D}$ alone on fracture incidence ${ }^{32}$.

Two recent studies have examined the effects of vitamin D in care-home residents, who are likely to be vitamin D deficient ${ }^{29,30}$. Law performed a cluster randomised trial of oral vitamin $\mathrm{D}_{2}(2.5 \mathrm{mg} ; 100000 \mathrm{IU})$ three-monthly in 3717 care-home residents ${ }^{29}$. Serum $25 \mathrm{OHD}$ in a small sub-set increased from 47 to $82 \mathrm{nmol} / \mathrm{l}$ after 1 month and $74 \mathrm{nmol} / \mathrm{l}$ after 3 months. Despite this improvement in vitamin D status, there was no reduction in falls (relative risk 1.09 $(95 \%$ CI $0.95,1.25))$ or fractures (relative risk $1.48(95 \%$ CI $0.99,2.20)$ ). A second randomised controlled trial by Lyons et al. examined the effect of oral vitamin $\mathrm{D}_{2}(2.5 \mathrm{mg}$; $100000 \mathrm{IU})$ four-monthly in 3440 care-home residents ${ }^{30}$. Baseline serum 25OHD measurements were not performed, but during the study these were 80 and $54 \mathrm{nmol} / 1$ respectively in a small sub-set of the intervention and control group. There was no reduction in fracture risk with vitamin D supplementation (hazard ratio 0.95 (95\% CI 0.8, 1.20)). 
Although there is controversy about what constitutes adequate vitamin D status, the recent studies of vitamin D supplementation suggest that the conservative thresholds adopted in the UK may be more appropriate than those advocated in North America. Combined Ca and vitamin D supplementation may decrease fracture risk in care-home residents, in whom vitamin $\mathrm{D}$ deficiency is common, but is probably ineffective in the prevention of fractures in community-dwelling older individuals. Future studies of vitamin D supplementation should include measurements of vitamin D status in a greater proportion of the participants than in previous trials, to investigate the relationship between putative benefits and the baseline and peak serum 25OHD concentrations achieved with supplementation.

\section{Other nutritional factors}

The effect of low BMI was examined in a recent meta-analysis in 14887 men and 44757 women from twelve prospective cohort studies $^{33}$. This showed little effect of BMI on fracture risk between 25 and $35 \mathrm{~kg} / \mathrm{m}^{2}$, but the risk of hip fracture increased dramatically as the BMI fell below $25 \mathrm{~kg} / \mathrm{m}^{2}$. The relative risk of hip fracture at a BMI of $20 \mathrm{~kg} / \mathrm{m}^{2}$ was 1.95 increasing to 4.48 at a BMI of $15 \mathrm{~kg} / \mathrm{m}^{2}$.

The effect of alcohol consumption was also examined in 5939 men and 11032 women from three prospective cohort studies ${ }^{34}$. This suggested that the risk of fractures increased in men drinking $\geqq 3$ units alcohol/d. Although the overall risk of osteoporotic fractures in women only increased with an intake of $\geqq 4$ units/d, hip fractures increased with only 3 units/d.

There has been growing interest in the role of fruit and vegetables in the maintenance of bone health. Studies show a beneficial effect on bone density and bone turnover markers, but there is no evidence yet of a reduction in fracture risk ${ }^{35}$. It is also currently unclear if the putative benefits of fruit and vegetable consumption are mediated in changes in acid-base balance, vitamin $\mathrm{K}$ or the consumption of antioxidants.

Although our knowledge of the effects of nutrition on bone health is gradually increasing, there are still a large number of unanswered questions. It is therefore important to remember Voltaire, who stated that 'only charlatans are certain... doubt is not a very agreeable state, but certainty is a ridiculous one.'

\section{Acknowledgements}

The present paper is based on the opening presentation at the Food Standards Agency Workshop on Nutrition and Bone Health, November 2006. The author is grateful for the helpful comments of participants attending the workshop. The views expressed are those of the author and do not necessarily reflect those of the Food Standards Agency or the workshop participants.

\section{References}

1. Department of Health (1991) Dietary Reference Values for Food Energy and Nutrients for the United Kingdom. Report on Health and Social Subjects no. 41. London: The Stationery Office.

2. Department of Health (1994) Advisory Group on Osteoporosis Report. London: Department of Health.
3. Department of Health (1998) Nutrition and Bone Health. London: The Stationery Office.

4. Expert Group on Vitamins and Minerals (2003) Safe Upper Limits for Vitamins and Minerals. London: Food Standards Agency.

5. World Health Organization (2003) Diet, Nutrition and the Prevention of Chronic Diseases. Geneva: World Health Organization.

6. Gregory J, Lowe S, Bates CJ, Prentice A, Jackson LV, Smithers G, Wenlock R \& Farron M (2000) National Diet and Nutrition Survey: Young People Aged 4 to 18 Years. London: The Stationery Office.

7. Henderson L, Irving K, Gregory J, Bates CJ, Prentice A, Perks J, Swan G \& Farron M (2003) National Diet and Nutrition Survey: Adults Aged 19 to 64 Years. Volume 3, Vitamin and Mineral Intake and Urinary Analytes. London: The Stationery Office.

8. Finch S, Doyle W, Lowe C, Bates CJ, Prentice A, Smithers G \& Clarke PC (1998) National Diet and Nutrition Survey: People Aged 65 Years and Over. Report of the Diet and Nutrition Survey, Volume 1, London: The Stationery Office.

9. Winzenberg T, Shaw K, Fryer J \& Jones G (2006) Effect of calcium supplementation on bone density in healthy children; meta-analysis of randomised controlled trials. $\mathrm{Br}$ Med $J \mathbf{3 3 3}$, 775-778.

10. Prentice A, Schoenmakers I, Laskey MA, de Bono S, Ginty F \& Goldberg GR (2006) Nutrition and bone growth and development. Proc Nutr Soc 65, 348-360.

11. Shea B, Wells G, Cranney A, et al. (2002) Meta-analyses of therapies for postmenopausal osteoporosis. VII Meta-analysis of calcium supplementation for the prevention of postmenopausal osteoporosis. Endocr Rev 23, 552-559.

12. Jackson RD, LaCroix AZ, Gass M, et al. (2006) Calcium plus vitamin D supplementation and the risk of fractures. $N$ Engl $J$ Med 354, 669-683.

13. Curhan GC, Willett WC, Speizer FE, Spiegelman D \& Stampfer MJ (1997) Comparison of dietary calcium with supplemental calcium and other nutrients as factors affecting the risk for kidney stones in women. Ann Intern Med 126, 497-504.

14. Holick MF (1994) McCollum Award Lecture, 1994, vitamin D - new horizons for the 21st century. Am J Clin Nutr 60, 619-630.

15. Armas LAG, Hollis BW \& Heaney RP (2004) Vitamin $D_{2}$ is much less effective than vitamin $\mathrm{D}_{3}$ in humans. J Clin Endocrinol Metab 89, 5387-5391.

16. Hirani V \& Primatesta P (2005) Vitamin D concentrations among people aged 65 years and over living in private households and institutions in England: population survey. Age Ageing 34, 485-491.

17. Lips P (2001) Vitamin D deficiency and secondary hyperparathyroidism in the elderly: consequences for bone loss and fractures and therapeutic implications. Endocr Rev 22, 477-501.

18. Vieth R, Ladak Y \& Walfish PG (2003) Age-related changes in the 25-hydroxyvitamin D versus parathyroid hormone relationship suggest a different reason why older adults require more vitamin D. J Clin Endocrinol Metab 88, 185-191.

19. Dawson-Hughes B, Heaney RP, Holick MF, Lips P, Meunier PJ \& Vieth R (2005) Estimates of optimal vitamin D status. Osteoporos Int 16, 713-716.

20. Lips P, Chapuy MC, Dawson-Hughes B, Pols HAP \& Holick MF (1999) An international comparison of serum 25-hydroxyvitamin D measurements. Osteoporos Int 9, 394-397.

21. Holick MF \& Jenkins M (2003) The UV Advantage. New York: ibooks.

22. Hypponen E \& Power C (2007) Hypovitaminosis D in British adults at age $45 \mathrm{y}$ : nationwide cohort study of dietary and lifestyle predictors. Am J Clin Nutr 85, 860-868.

23. Heaney RP, Davies KM, Chen TC, Holick MF \& Barger-Lux MJ (2003) Human serum 25-hydroxycholecalciferol response 
to extended oral dosing with cholecalciferol. Am J Clin Nutr $\mathbf{7 7}$, 204-210.

24. Hathcock JN, Shao A, Vieth R \& Heaney R (2007) Risk assessment for vitamin D. Am J Clin Nutr 85, 6-18.

25. Bischoff-Ferrari HA, Willett WC, Wong JB, Giovannucci E, Dietrich T \& Dawson-Hughes B (2005) Fracture prevention with vitamin D supplementation: a meta-analysis of randomized controlled trials. JAMA 293, 2257-2264.

26. Smith H, Anderson F, Raphael H, Crozier S \& Cooper C (2004) Effect of annual intramuscular vitamin D supplementation on fracture risk: population-based, randomised, double-blind, placebo-controlled trial. Osteoporos Int 15, Suppl. 1, S8.

27. Grant AM, Avenell A, Campbell MK, et al. (2005) Oral vitamin D3 and calcium for secondary prevention of low-trauma fractures in elderly people (Randomised Evaluation of Calcium Or vitamin D, RECORD): a randomised placebo-controlled trial. Lancet 365, 1621-1628.

28. Porthouse J, Cockayne S, King C, et al. (2005) Randomised controlled trial of calcium and supplementation with cholecalciferol (vitamin D3) for prevention of fractures in primary care. Br Med J 330, 1003-1006.

29. Law M, Withers H, Morris J \& Anderson F (2006) Vitamin D supplementation and the prevention of falls and fractures: results of a randomised controlled trial in elderly people in residential accommodation. Age Ageing 35, 482-486.
30. Lyons RA, Johansen A, Brophy S, Newcombe RG, Phillips CJ, Lervy B, Evans R, Wareham K \& Stone MD (2007) Preventing fractures among older people living in institutional care: a randomised double blind placebo controlled trial of vitamin D supplementation. Osteoporos Int 18, 811-818.

31. Avenell A, Gillespie W, Gillespie L \& O'Connell D (2005) Vitamin D and vitamin D analogues for preventing fractures associated with involutional and post-menopausal osteoporosis. In The Cochrane Database of Systematic Reviews 2005, issue 3, CD000227. http://www.mrw.interscience.wiley.com/cochrane/ clsysrev/articles/CD000227/frame.html.

32. Boonen S, Lips P, Bouillon R, Bischoff-Ferrari HA, Vanderschueren D \& Haentjens P (2007) Need for additional calcium to reduce the risk of hip fracture with vitamin D supplementation: evidence from a comparative meta-analysis of randomized controlled trials. $J$ Clin Endocrinol Metab 92, 1415-1423.

33. De Laet C, Kanis JA, Oden A, et al. (2005) Body mass index as a predictor of fracture risk: a meta-analysis. Osteoporos Int 16, $1330-1338$

34. Kanis JA, Johannson H, Johnell O, et al. (2005) Alcohol intake as a risk factor for fracture. Osteoporos Int 16, 737-742.

35. Burns L, Ashwell M, Berry J, et al. (2003) UK Food Standards Agency Optimal Nutrition Status Workshop: environmental factors that affect bone health throughout life. Br J Nutr 89, $835-840$. 